\title{
KAP study on the dietary pattern among regular gym members in Majmaah city, Saudi Arabia
}

\author{
Syed Meraj Ahmed 1,*, Eyad Mohammed Alodhaydan ${ }^{2}$, Ahmad Hamad Alhammad ${ }^{3}$, Sami Suliman \\ Alabdulqadir 4 , Abdulaziz Abdulrahman Alhassan ${ }^{5}$, Mohammed Daham Alrafedi6 $^{6}$ \\ ${ }^{\mathbf{1}}$ Associate Professor, ${ }^{\mathbf{2 , 3 , 4 , 5 , 6}} 4^{\text {th }}$ Year MBBS Student, Dept. of Community Medicine, College of Medicine, Majmaah University, \\ Majmaah, Saudi Arabia
}

*Corresponding Author:

Email: merajahmed10@ hotmail.com

\begin{abstract}
An increasing trend of motivated individuals joining the gym for improving their fitness is an encouraging sign. Additionally, an attitudinal change in the dietary intake should also be a part of this routine to help achieve a healthy body and mind. Studies have shown that addressing the promotion of healthy eating, particularly when combined with the practice of physical activity, show satisfactory results when it comes to the control of diabetes and cardiovascular diseases. A need was felt to conduct a baseline study to find out the attitude and behavioural preferences in terms of diet and exercise. This is a cross sectional study done on 164 male gym members. A pretested, preformed interviewee based, close ended questionnaire was used to collect data from the study participants in a time bound manner. Analysis was done through SPSS software. Intake of carbonated drinks $(79.2 \%, \mathrm{p}<0.01)$ and fruit juices $(83.3 \%)$ were significantly higher among regular members in comparison to those who visited the gym infrequently. Consumption of milk (72.9), eggs $(45.8 \%)$, butter $(45.8 \%, \mathrm{p}<0.001)$ and fish $(43.8 \%)$ was also higher among regular members. Alternatively, it was seen that beef consumption was higher among regular gym goers and $74.4 \%$ of them didn't follow any specific diet for maintaining health. There is a general lack of awareness and attitude towards the type of healthy food required for maintaining health and preventing health disorders particularly non - communicable diseases.
\end{abstract}

Keywords: Dietary goals, Gym, Youth, Healthy diet, Dietary habit, Saudi Arabia.

\section{Introduction}

To favour an increase in the fruit and vegetable intake among the general population is one of the major concerns and aims of health promotion programs across the world. ${ }^{1}$ The pattern of eating food either the amount or the frequency determines the health status of the individual and subsequently the type of eating disorder (diabetes, hypertension etc.) that will develop if it remains uncontrolled. ${ }^{2}$ A study found that specifically, increasing consumption of fruits and vegetables, whole grains, and calcium-rich foods, while reducing saturated fats, trans fats, sodium, added sugars, and excess calories and reducing obesity could dramatically improve an individual's health and well-being. ${ }^{3}$ Another study also concluded that the risk of developing a major non-communicable disease, the leading cause of death in the world, is decisively affected by lifestyle choices. ${ }^{4}$ A thought provoking issue with the growing youth in Saudi Arabia is the development of obesity and/or being overweight which consequently brings the risk of associated health disorders with it. ${ }^{5}$ Adopting a lifestyle contrary to the development of a healthy body and mind can lead to health consequences. Lopez et $\mathrm{al}^{6}$ found in their study that smoking, physical inactivity, unhealthy diet, obesity and other lifestyle behaviours are associated with the development of diseases such as cancer, heart disease, stroke, and diabetes.

Recently there has been a trend of joining a health center or a gym for improving the physique or losing weight to gain that healthy body which will be beneficial in warding off any chronic metabolic related health disorders. Andrew $\mathrm{K}$ Chen et $\mathrm{al}^{7}$ in their study found that if a short-term rigorous diet and exercise regimen is instituted even among youths, then it can reverse metabolic syndrome. Another study on women determined that motivation to regulate eating habits was connected in a major way to regular exercise motivation. ${ }^{8}$ A review article concluded that regular exercise improves the cardiovascular status, reduces the risk of cardiac disease, high blood pressure and cerebrovascular disease which is due to a reduction in body weight, improved insulin sensitivity leading to a good glycemic control. ${ }^{9}$

It is essential that a dietary modification be ensured along with a program for regular exercise to bring about the maximum change in the health status and studies on targeted populations found that multicomponent lifestyle intervention did induce positive health changes in participants with a range of sociodemographic characteristics and food shopping and eating behaviours. ${ }^{10-11}$ These health disorders can also be attributed to a fast way of life with easy access to food particularly those which are available over the counter or in fast food restaurants. A study on such food items available in food kiosks was done and it was found to be of low nutritional quality. ${ }^{12}$

A need was felt on studying the perception of people regarding quality of food intake who are engaged in doing regular exercises. Studies have shown that there is not enough awareness regarding healthy dietary choices among young people who exercise to maintain a healthy lifestyle. ${ }^{13-15}$ Even though there is an 
increased awareness about keeping fit through sport and exercise activities among the young population in Saudi Arabia, there are very few literature seven within the Middle East, which shows any relationship or consequences of dietary behaviour associated with physical activities. ${ }^{16-17}$ Some studies showed that irregular and infrequent meals together with low vegetables and fruits intake were the most common unhealthy eating habits among the survey participants in Saudi Arabia. ${ }^{18-20}$

This will be a pilot study on the behavioural attitude of people who are regular members of their local gym towards dietary preferences. It will attempt to identify any change in the eating habits and the quality of the food intake among the participants who want to be fit and healthy through regular exercise either supervised or unsupervised.

\section{Aims and Objectives}

Primary Objective: To assess the dietary preferences among regular members of a gym or sporting facility.

\section{Secondary Objective:}

1. To assess the knowledge about healthy diet among the study participants.

2. To assess the attitude towards dietary goals among study participants.

3. To determine the practice followed in maintaining a healthy diet intake.

\section{Materials and Methods}

Study Design: This is a cross sectional, observational and questionnaire-based study to assess the knowledge, attitude and practices of gym goers towards healthy nutrition.

Study Setting: The study was conducted in Majmaah city, Saudi Arabia. Majmaah is a city and a governorate in Ar Riyad Province, Saudi Arabia. It is located at around $25^{\circ} 54^{\prime} 14^{\prime \prime} \mathrm{N} 45^{\circ} 20^{\prime} 44^{\prime \prime} \mathrm{E}$, and has an area of 30 000 square kilometres. The population of the town is around $45,000 .^{21}$

Target Population: This study was conducted among all the male gym members who are registered with the government owned and private gym in Majmaah.
Duration of the Study: The total duration including data collection took around six months for the completion of the study from December 2015 to May 2016.

Sampling Technique: A complete enumeration method was used to include all the male gym members who were actively registered during the period of data collection.

Data Collection: A pretested, preformed interviewee based, close ended questionnaire was used to collect data from the study participants in a time bound manner.

Data Analysis: All the data was entered in to the SPSS software and statistical analysis done to find out the knowledge, attitude and practice of gym goers towards a healthy and nutritional diet. A 95\% degree of freedom with p-value of $<0.05$ was considered as statistically significant.

Ethical Considerations: A written consent from the gym members was taken after they were briefed about the objective of this study and the advantage to them as well as to the community due to their participation. They were also informed that all the information was kept purely confidential and was used only for the purpose of statistical analysis.

Limitations: Participation of the study population is purely voluntary so there will be some attrition. Information and recall bias due to lack of time to participate needs to be taken into consideration.

Inclusion and exclusion criteria: All the gym members who are working or residing in Majmaah city were included in the study. Any study participants who voluntarily refused to participate in the study were excluded.

\section{Result}

This study was conducted on 164 male participants who were regular members of a gym in Majmaah, Saudi Arabia. All the participants agreed to fill out the questionnaire and there were no missing data. Most of them were educated youngsters and the mean age of the participant was $24.47 \pm 5.25$ years (Fig. 1). As can be seen from Table 1 most of the participants who worked out in the gym were between $21-30$ years old $(83.5 \%)$.

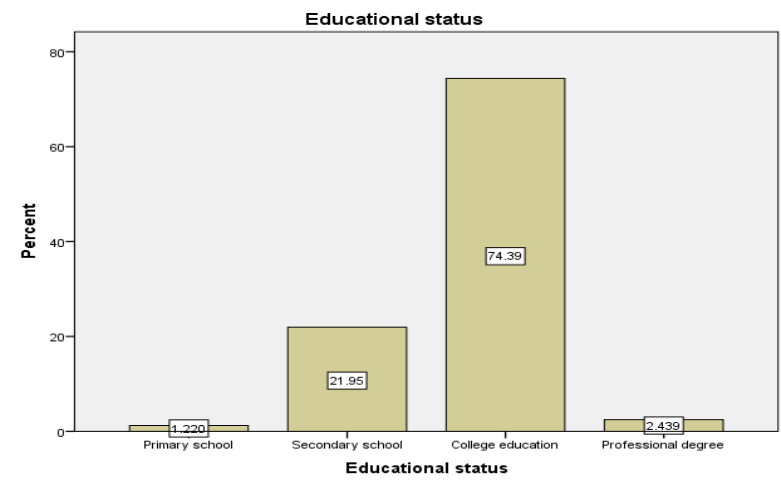

Fig. 1: Educational status of participants 
Table 1: Frequency of workout in the gym

\begin{tabular}{|l|c|c|c|c|}
\hline \multirow{2}{*}{} & \multicolumn{2}{|c|}{ Frequency of workout in the gym } & \multirow{2}{*}{ Total } \\
\cline { 2 - 4 } & daily & $\mathbf{1 - 2}$ days a week & 3-6 days a week & \\
\hline $15-20$ years & $9(56.2 \%)$ & $4(25.0 \%)$ & $3(18.8 \%)$ & $16(100.0 \%)$ \\
\hline $21-25$ years & $27(24.8 \%)$ & $33(30.3 \%)$ & $49(45.0 \%)$ & $109(100.0 \%)$ \\
\hline $26-30$ years & $9(32.1 \%)$ & $13(46.4 \%)$ & $6(21.4 \%)$ & $28(100.0 \%)$ \\
\hline $31-35$ years & $1(33.3 \%)$ & $1(33.3 \%)$ & $1(33.3 \%)$ & $3(100.0 \%)$ \\
\hline$>36$ years & $2(25.0 \%)$ & $3(37.5 \%)$ & $3(37.5 \%)$ & $8(100.0 \%)$ \\
\hline Total & $48(29.3 \%)$ & $54(32.9 \%)$ & $62(37.8 \%)$ & $164(100.0 \%)$ \\
\hline
\end{tabular}

An assessment of the choice for fluids and fruits in the diet in Table 2 shows that the intake of carbonated drinks (coke, sprite etc.) was quite significantly higher $(\mathrm{p}<0.010)$ among even those who worked out daily (79.2\%) as when compared to those who didn't. More of the participants who worked out daily drank milk $(72.9 \%)$ then those who didn't work out daily. Fruit juice $(83.3 \%)$ and fruits $(83.0 \%)$ were also preferred more by regular gym goers but it was not statistically significant.

Table 2: Dietary choices among participants

\begin{tabular}{|c|c|c|c|c|}
\hline \multirow[b]{2}{*}{ Dietary choices } & \multicolumn{3}{|c|}{ Workout in the gym } & \multirow[b]{2}{*}{$\chi^{2}$ test at $95 \% \mathrm{CI}$} \\
\hline & Daily & $\begin{array}{c}\text { - } 2 \text { days / } \\
\text { week }\end{array}$ & 3 - 6 days / week & \\
\hline Drinks milk daily & $35(72.9 \%)$ & $39(72.2 \%)$ & $38(61.3 \%)$ & $p<0.323$ \\
\hline Drinks fruit juice daily & $40(83.3 \%)$ & $42(77.8 \%)$ & $50(80.6 \%)$ & $p<0.778$ \\
\hline Drinks carbonated beverages daily & $38(79.2 \%)$ & $36(66.7 \%)$ & $32(51.6 \%)$ & $\mathrm{p}<\mathbf{0 . 0 1 0}$ \\
\hline Eats fruits (apples/pears) daily & $39(83.0 \%)$ & $40(75.5 \%)$ & $52(83.9 \%)$ & $\mathrm{p}<0.474$ \\
\hline Eats eggs (at least one) daily & $22(45.8 \%)$ & $18(33.3 \%)$ & $26(41.9 \%)$ & $p<0.413$ \\
\hline Eats fish more than twice a week & $21(43.8 \%)$ & $13(24.1 \%)$ & $17(27.4 \%)$ & $\mathrm{p}<0.074$ \\
\hline Eats beef daily & $5(10.4 \%)$ & $4(7.4 \%)$ & $10(16.1 \%)$ & $\mathrm{p}<0.327$ \\
\hline Eats rice or pasta daily & $17(35.4 \%)$ & $18(33.3 \%)$ & $19(30.6 \%)$ & $\mathrm{p}<0.886$ \\
\hline Eating outside food $>1$ weekly & $25(52.1 \%)$ & $35(64.8 \%)$ & $31(50.0 \%)$ & $\mathrm{p}<0.403$ \\
\hline Includes butter in the diet & $22(45.8 \%)$ & $9(16.7 \%)$ & $9(14.5 \%)$ & $\mathbf{p}<0.000$ \\
\hline Takes $>2-3$ tsp of sugar per day & $4(8.3 \%)$ & $9(16.7 \%)$ & $6(9.7 \%)$ & $\mathrm{p}<0.354$ \\
\hline $\begin{array}{l}\text { Follow a special diet for weight } \\
\text { loss }\end{array}$ & $13(27.1 \%)$ & $8(14.8 \%)$ & $21(33.9 \%)$ & $\mathrm{p}<0.061$ \\
\hline
\end{tabular}

The regular gym goers to have more preferences for daily intake of milk (72.9) and eggs (45.8\%) as compared to the rest of the group though not statistically significant. They also eat more fish each week $(43.8 \%, \mathrm{p}<0.07)$ as compared those members who don't come to the gym daily. Even though most of the gym members do not prefer eating beef on a daily basis but the habit of eating beef among those visiting the gym $3-6$ times a week is more $(16.1 \%, \mathrm{p}<0.327)$ than those who are daily gym goers.

The attitude of the regular gym goers who wants to lose weight preferring to take butter in their diet $(45.8 \%)$ which is quite significantly higher $(\mathrm{p}<0.000)$ than those who are not exercising daily. Also, most of them prefer eating out more than once weekly $(55.5 \%)$ instead of eating home cooked food which is an unhealthy practice. Also, a huge $74.4 \%$ do not follow any special diet for weight loss or maintaining a healthy weight and this is seen particularly among those who works out 3 - 6 days a week (33.9\%).

\section{Discussion}

This study attempts to find out the behaviour of gym goers towards nutritious diet and it can be said that consumption of milk on a regular basis is very important for the development of muscle mass and loss of fat. ${ }^{22}$ As seen in our study the consumption of milk and eggs daily is higher among regular gym goers and this is supported by similar studies done in Saudi Arabia. ${ }^{23-24}$ Despite a high awareness of regular exercise to remain fit among the gym goers, their addiction to an unhealthy habit of consuming carbonated beverages is also very high. This is detrimental to the goal of achieving a health body as shown in other studies that supports this view..$^{25-26}$

Our study shows that beef consumption on a regular basis is quite low which is important to reduce the weight and prevent obesity and heart disease. But there is not much difference in consumption pattern associated with the frequency of visit to the gym which shows a lack of awareness regarding its harmful effect. In a study done in UK it was shown that non - beef eaters were thinner than beef eaters. ${ }^{27}$ 
The frequency of consuming food from outside home particularly in fast food restaurants etc. is quite high in Saudi Arabia and in our study, we have seen that most of the participants prefer having food from outside (52.1\% to $64.8 \%$ ) which is again contrary to the concept of good health. This is supported by many studies that have shown that consumption of foods frequently sold at "fast food" restaurants (e.g. hamburgers and French fries) is positively associated with increase in body weight. ${ }^{28-31}$

A higher consumption of saturated fat (butter) among the participants shows a lack of awareness regarding its detrimental effects also seen in other studies done around the world regarding the intake of more fibre, sodium, and total, saturated, and polyunsaturated fat that leads to an increase in body mass index. ${ }^{32-34}$ This study also found that quite a few of the participants were following a special diet for maintaining weight which showed that they had knowledge about the benefits of such dietary practices to their health. This is supported by the WHO article that promotes the use of special diets and healthy lifestyle that helps in maintaining good health and immunity. ${ }^{35}$

\section{Conclusion}

In conclusion, this study has shown that even though the executable concept of going to the gym has gained popularity among the youths, there is still a felt need to make them aware about the benefits of healthy diet and lifestyle choices. This can be achieved through social media, workplace awareness programs, inclusion in educational curricula in schools and colleges etc. Furthermore, support of friends, families, institutions, local and national organizations, political empowerment is the need of the hour.

\section{Recommendation}

This study provides ample background information on those people who are quite aware about the benefits of doing regular exercise in a controlled environment (gym) but have limited knowledge and awareness about dietary modifications required to improve their overall health. We would like to recommend more health education on dietary preferences targeted towards the younger generation and particularly towards motivated youngsters who frequent the gym to remain fit. This can be done through distribution of pamphlets, sticking banners, using the electronic and social media including group activities in schools and colleges. Also, the gym should be targeted to provide nutritional guidance by the coaches along with physical activities to enhance the positive effect of an improved lifestyle.

\section{Acknowledgement}

We acknowledge the kind contribution of the Department of Community Medicine and Research for showing immense confidence in our participation in the study including encouraging us to try harder and make the most of this opportunity.

\section{References}

1. World Health Organization. Fruit and Vegetable Promotion Initiative. Available at:

http://www.who.int/hpr/NPH/fruit_and_vegetables/fruit_and _vegetable_report.pdf Accessed on 06.05.2016

2. Xavier Pi Sunyer F. Health implication of obesity. Am J Clir Nutr. 1991;53:15953-16035.

3. US Dep. Health Hum. Serv./US Dep. Agric. 2005. Dietary Guidelines for Americans 2005. Washington, DC: USGPO.

4. WHO (2011) Available from http://www.who.int/research/en/, accessed on 05.05.2016.

5. Al-Hazzaa HM. Prevalence and trends in obesity among school boys in Central Saudi Arabia between 1988 and 2005. Saudi Medical Journal. 2007;28(10):1569-1574.

6. Lopez AD, Mathers CD, Ezzati M, Jamison DT, Murray CJL. Global and regional burden of disease and risk factors, 2001: systematic analysis of population health data. Lancet. 2006;367:1747-1757.

7. Chen AK, Roberts CK, Barnard RJ. Effect of a short-term diet and exercise intervention on metabolic syndrome in overweight children. Science Direct. 2006;55(7):871-878.

8. Mata J, Silva MN, Vieira PN, Carraça EV, Andrade AM, Coutinho SR, et al. Motivational "spill-over" during weight control: Increased self-determination and exercise intrinsic motivation predict eating self-regulation. Health Psychol. 2009;28(6):709-16.

9. Siddiqui NI, Nessa A, Hossain MA. Regular physical exercise: way to healthy life; Mymensingh. Med J. 2010;19(1):154-8.

10. Thomson JL, Zoellner JM, Tussing-Humphreys LM, Goodman MH. Moderators of intervention dose effects on diet quality and physical activity changes in a church-based, multicomponent, lifestyle study: Delta Body and Soul III. Health Educ Res. 2016;31(3):339-49.

11. Schweitzer AL, Ross JT, Klein CJ, Lei KY, Mackey ER. An electronic wellness program to improve diet and exercise in college students: a pilot study. JMIR Res Protoc. 2016;5(1):e29.

12. Park H, Papadaki A. Nutritional value of foods sold in vending machines in a UK University: Formative, crosssectional research to inform an environmental intervention. Appetite. 2016;96:517-25.

13. Anding JD, Suminiski RR, Boss L. Dietary intake, body mass index, exercise and alcohol: are college women following the dietary guidelines? J Am Coll Health. 2001;49:167-171.

14. Al-Almaie S. Knowledge of healthy diets among adolescents in Eastern Saudi Arabia. Ann Saudi Med. 2005;25:294-298.

15. Al-Refaee S, Al-Hazza HM. Physical activity profile of Saudi males: implications for health. Saudi Med J. 2001;22:784-789.

16. Sulaiman N, Hamdan A, Al-Bedri DM, Young D. Diabetes knowledge and attitudes towards prevention and health promotion; qualitative study in Sharjah, United Arab Emirates. International Journal of Food Safety, Nutrition and Public Health. 2009;2:78-88.

17. Midhet FM, Sharaf FK. Impact of health education on lifestyles in Central Saudi Arabia. Saudi Med J. 2011;32(1):71-76.

18. Al-Rethaiaa AS, Fahmy AE, Al-Shwaiyat NM. Obesity and eating habits among college students in Saudi Arabia: a cross sectional study. Nutr J. 2010 Sep 19;9:39.

19. Alsaif MA, Hakim IA, Harris RB, Alduwaihy M, AlRubeaan K, Al-Nuaim AR, et al. Prevalence and risk factors 
of obesity and overweight in adult Saudi population. Nutr Res. 2002;22:1243-1252.

20. Al-Nozha MM, Al-Mazrou YY, Al-Maatouq MA, Arafah MR, Khalil MZ, Khan NB, et al. Obesity in Saudi Arabia. Saudi Med J. 2005;26(5):824-829.

21. Al Majma'ah. Wikipedia. Available on: https://en.wikipedia.org/wiki/Al_Majma\%27ah. Accessed on 06.05.2016.

22. Hartman JW, Tang JE, Wilkinson SB. Consumption of fatfree fluid milk after resistance exercise promotes greater lean mass accretion than does consumption of soya or carbohydrate in young, novice, male weightlifters. Am J Clin Nutr. 2007;86(2):373Y81.

23. Farghaly NF, Ghazali BM, Al-Wabel HM, Sadek AA, Abbag FI. Life style and nutrition and their impact on health of Saudi school students in Abha, Southwestern region of Saudi Arabia. Saudi Medical Journal. 2007;28(3):415-21.

24. Abahussain NA, Musaiger AO, Nicholls PJ, Stevens R. Nutritional status of adolescent girls in the eastern province of Saudi Arabia. Nutr Health. 1999;13:171-177.

25. Mahfouz AA, Shatoor AS, Khan MY, Daffalla AA, Mostafa OA, Hassanein MA. Nutrition, physical activity, and gender risks for adolescent obesity in Southwestern Saudi Arabia. Saudi Journal of Gastroenterology. 2011;17(5):318.

26. Kant AK, Graubard BI. Secular trends in patterns of selfreported food consumption of adult Americans: NHANES 1971-1975 to NHANES 1999-2002. Am J Clin Nutr. 2006;84:1215-23.

27. Appleby PN, Thorogood M, Mann JI, Key TJ. Low body mass index in non-meat eaters: the possible roles of animal fat, dietary fibre and alcohol. International Journal of Obesity. 1998;22(5):454-60.
28. Jeffery RW, French SA. Epidemic obesity in the United States: Are fast foods and television viewing contributing? Am J Public Health. 1998;88(2):277-280.

29. French SA, Harnack L, Jeffery RW. Fast food restaurant use among women in the Pound of Prevention study: Dietary, behavioral and demographic correlates. Int J Obes. 2000;24:1353-1359.

30. Prentice AM, Jebb SA. Fast foods, energy density and obesity: A possible mechanistic link. Obes Rev. 2003;4:187194.

31. French SA, Story M, Neumark-Sztainer D, Fulkerson JA, Hannan P. Fast food restaurant use among adolescents: associations with nutrient intake, food choices and behavioural and psychosocial variables. Int J Obes Relat Metab Disord. 2001;25:1823-1833.

32. Mente A, de Koning L, Shannon HS, Anand SS. A systematic review of the evidence supporting a causal link between dietary factors and coronary heart disease. Archives of Internal Medicine. 2010;169(7):659-69.

33. Anderson JW, Baird P, Davis RH, Jr, Ferreri S, Knudtson $\mathrm{M}$, Koraym A, et al. Health benefits of dietary fiber. Nutrition Reviews. 2009;67(4):188-205.

34. Reeves MJ, Rafferty AP. Healthy lifestyle characteristics among adults in the United States, 2000. Arch Intern Med. 2005;165(8):854-7.

35. Waxman A. WHO's global strategy on diet, physical activity and health. Response to a worldwide epidemic of non-communicable diseases. Food and Nutrition Research. 2004;48(2):58-60. 